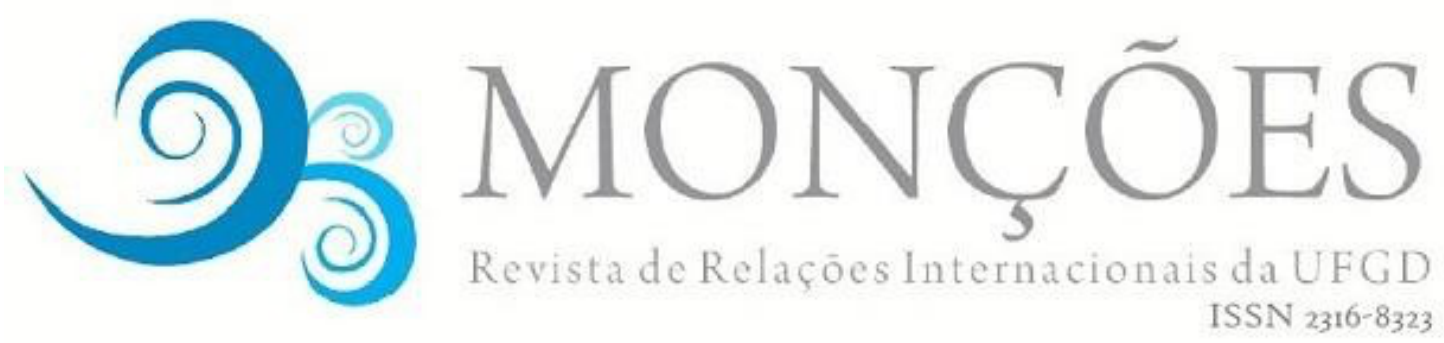

\title{
CRÍTICA AO CONCEITO DE SUBIMPERIALISMO: A DIMENSÃO SUL- AMERICANA DA POLÍTICA EXTERNA BRASILEIRA E AS LIMITAÇÕES DAS ANÁLISES DEPENDENTISTAS
}

\author{
TIAGO SOARES NOGARA \\ Universidade de Brasília (UnB), mestrando no Programa de Pós-Graduação em \\ Relações Internacionais (PPGRI), Brasília/DF, Brasil. \\ ORCID: https://orcid.org/0000-0003-1560-8150 \\ tiagosnogara@gmail.com
}

Resumo: $O$ artigo a visa analisar o conceito de subimperialismo, inerente à Teoria Marxista da Dependência (TMD), verificando sua formulação, aplicação e validade para caracterizar a dimensão sul-americana da política externa brasileira ao longo dos governos Lula (2003-2010). A hipótese do trabalho é de que o conceito apresenta limitações para definir a inserção internacional brasileira, reproduzindo visões que contraditoriamente afirma desafiar. Na primeira seção, será apresentado um resgate teórico da formulação do conceito de subimperialismo. Em seguida, serão expostas as principais críticas à política externa brasileira embasadas no conceito de subimperialismo. Por fim, essas críticas serão contrapostas às proposições da política externa brasileira com relação às temáticas da integração regional e das relações bilaterais com países sul-americanos.

Palavras-chave: subimperialismo brasileiro; teoria marxista da dependência; integração sul-americana.

\section{CRITICISM OF THE CONCEPT OF SUBIMPERIALISM: THE SOUTH AMERICAN DIMENSION OF BRAZILIAN FOREIGN POLICY AND THE LIMITATIONS OF DEPENDENTIST ANALYZES}

\begin{abstract}
The article aims to analyze the concept of sub-imperialism, inherent to the Marxist Theory of Dependence (TMD), verifying its formulation, application and validity to conceptualize the South American dimension of Brazilian foreign policy throughout the Lula governments (2003-2010). The hypothesis of the work is that the concept has limitations to define the Brazilian international insertion, reproducing visions that it claims to challenge. In the first section, a theoretical review of the concept of subimperialism will be presented. Then, the main criticisms of Brazilian foreign policy based on the concept of sub-imperialism will be exposed. Finally, these criticisms will be opposed to the propositions of Brazilian foreign policy regarding regional integration and bilateral relations with South American countries.
\end{abstract}

Keywords: Brazilian subimperialism; Marxist dependency theory; South American integration. 


\title{
CRÍTICA AL CONCEPTO DE SUBIMPERIALISMO: LA DIMENSIÓN SUDAMERICANA DE LA POLÍTICA EXTERIOR BRASILEÑA Y LAS LIMITACIONES DE LOS ANÁLISIS DEPENDENTISTAS
}

\begin{abstract}
Resumen: El artículo tiene como objetivo analizar el concepto de subimperialismo, de la Teoría Marxista de la Dependencia (TMD), verificando su formulación, aplicación y validez para caracterizar la dimensión sudamericana de la política exterior brasileña durante los gobiernos de Lula (2003-2010). La hipótesis del trabajo es que el concepto tiene limitaciones para definir la inserción internacional brasileña, reproduciendo visiones que dice combatir. En la primera sección, se presentará una revisión teórica de la formulación del concepto de subimperialismo. Luego, se expondrán las principales críticas a la política exterior brasileña basadas en el concepto de subimperialismo. Finalmente, estas críticas se opondrán a las propuestas de la política exterior brasileña con respecto a los temas de integración regional y relaciones bilaterales con los países sudamericanos.
\end{abstract}

Palabras clave: Subimperialismo brasileño; Teoria Marxista de la Dependencia; Política exterior brasileña.

\section{Introdução}

A primeira década do século XXI foi marcada por uma franca ascensão da participação do Brasil na construção de iniciativas multilaterais nos âmbitos global e regional, com o país protagonizando a constituição de arranjos de integração regional e intercontinental, e de fóruns com relevante importância para as discussões acerca das transformações correntes no equilíbrio de poder das relações internacionais. Embora haja fartura de textos que enfatize positivamente essas iniciativas brasileiras, de forma alguma elas escaparam às críticas, fossem pelas suas respectivas insuficiências ou até mesmo por supostas motivações predatórias implícitas em suas formulações. Esta última característica foi particularmente valorizada pelo resgate do conceito de subimperialismo, inerente à Teoria Marxista da Dependência (TMD), utilizado recorrentemente em interpretações críticas ao perfil da inserção internacional brasileira.

Apesar da bibliografia alinhada às teses do subimperialismo ser relativamente extensa, poucos foram os trabalhos que buscaram questioná-la, fenômeno que debilita o debate conceitual, afinal raras lacunas foram identificadas diante dos fundamentos que estruturam essa perspectiva, francamente hostil às iniciativas diplomáticas do gigante sul-americano no período. Ciente desse panorama, o artigo visa contribuir para o preenchimento dessa lacuna, traçando uma retrospectiva dos 
principais textos que teceram críticas à política externa brasileira a partir do conceito de subimperialismo, debatendo suas estruturas analíticas e contrapondo-os à realidade que reivindicam definir. A hipótese do trabalho é de que o conceito de subimperialismo apresenta limitações que o impedem de categorizar a política externa brasileira do período, reforçando uma visão sistêmica abstraída das condições materiais que constituem a atual ordem internacional e reafirmando estruturas que discursivamente alegam antagonizar, ao negarem aos países periféricos a capacidade de, alheios às revoluções sociais, formularem estratégias nacionais para a superação do subdesenvolvimento.

Valendo-se das contribuições de Fernandes (2000), partiremos do princípio de que a apreciação da validade de teorias no âmbito geral das ciências sociais há de ser remetida à evolução histórica dos fenômenos sociais que elas pretendem explicar. Dessa forma, dividiremos o artigo em quatro seções, visando debater o conceito, sua aplicação e validade. Na primeira seção, será apresentado um resgate do conceito de subimperialismo a partir dos pressupostos da Teoria Marxista da Dependência, com um atento detalhamento das observações de seu patrono, Ruy Mauro Marini, e de seus seguidores. Em seguida, serão expostas as principais críticas embasadas no conceito de subimperialismo à dimensão sul-americana da política externa brasileira ao longo dos governos Lula (2003-2010) - ápice do protagonismo regional do país no começo do século XXI -, ressaltando suas similitudes e inovações com relação às anteriores colocações de Marini. Por fim, nas duas últimas etapas, o conceito em questão será contraposto aos pilares de sustentação das teorias que advoga reproduzir, especificamente à teoria leninista do imperialismo, e ao perfil das proposições da política externa brasileira para a América do Sul, com especial atenção às temáticas de integração regional e das relações bilaterais com países sulamericanos.

\section{A Teoria Marxista da Dependência e o conceito de subimperialismo}

A Teoria Marxista da Dependência constitui a versão dependentista que interpreta, a partir da teoria marxista e da teoria clássica do imperialismo, a condição dependente das sociedades periféricas como uma consequência dos padrões de 
reprodução de capital em vigor na economia capitalista mundial (CARCANHOLO, 2013). Surgida na metade da década de 1960, representou um esforço teórico para compreender os limites do desenvolvimento econômico tardio, e crítico tanto das teses desenvolvimentistas quanto das visões marxistas que valorizavam políticas de aliança com as burguesias nacionais. A teoria a que fazemos alusão não se confunde, portanto, com o pensamento teórico da CEPAL e do ISEB, tampouco com as interpretações da dependência associada, apontadas por Bresser-Pereira (2010) como as outras duas vertentes da Teoria da Dependência. No Brasil, a TMD teve como seus principais precursores nomes como os de Ruy Mauro Marini, Theotônio dos Santos e Vânia Bambirra, sendo o conceito de subimperialismo uma produção teórica de Marini, com definição mais apurada em sua obra Subdesarrollo $y$ Revolución.

Ao interpretar a dependência enquanto um fenômeno inerente à própria condição de país periférico no sistema capitalista, ou seja, imutável dentro das próprias leis de reprodução do capital, Marini e os dependentistas marxistas convergiram no ponto que veio a sustentar seus principais posicionamentos políticos. Para eles, a única maneira de superar a dependência seria pela via de uma revolução social, que despojasse as elites locais e imperialistas do comando do país e permitisse uma ampla reorganização do sistema produtivo, de forma a atender prioritariamente às necessidades da população local. Assim, o empreendimento de uma ampla reforma agrária e a cessação dos mecanismos de superxploração do trabalho permitiriam a expansão do mercado interno, abrindo novas possibilidades para o desenvolvimento nacional. Essa compreensão levou Marini a participar da construção da Organização Revolucionária Marxista Política Operária (ORM-POLOP), às vésperas do golpe de 1964, contestando a estratégia aliancista do Partido Comunista Brasileiro (PCB) com setores da burguesia nacional, conclamando a mobilização popular e a tomada direta do poder. Quando exilado no Chile, Marini seguiu o mesmo rumo, se aproximando do Movimiento de la Izquierda Revolucionária (MIR), contestador da política de alianças do Partido Socialista (PS) e do Partido Comunista do Chile (PCCh) - em parte voltados para a manutenção de laços com a Democracia Cristã -, propondo, em seu lugar, um rompimento com o reformismo e a opção pela 
luta armada ${ }^{1}$, conclamada na principal palavra de ordem do próprio MIR: povo, consciência e fuzil.

Na visão de Marini (1974), no período prévio ao golpe de 1964 o ciclo de reprodução do capital no Brasil estava amparado em dois pilares: o progressivo aumento dos níveis de produtividade e a constante depreciação da remuneração das grandes massas trabalhadoras. $\mathrm{O}$ aumento das taxas de lucro decorria, portanto, tanto da utilização de novas tecnologias quanto da constante supressão dos índices salariais dos trabalhadores, submetidos ao que 0 autor conceituou de superexploração do trabalho. Essas tendências geravam um impasse, ao achatar o mercado interno e gerar problemas para a realização do capital no Brasil. E foi a partir dos desdobramentos dessa contradição que Marini desenvolveu seu conceito de subimperialismo, bem como sua visão acerca dos principais acontecimentos políticos brasileiros ocorridos daí em diante.

Visando sanar as limitações do mercado interno, os governos militares atuaram em duas frentes: o fomento do consumo público e a abertura de mercados no exterior (MARINI, 1971). No primeiro caso, a expansão do consumo não se concentrou no aumento do poder de compra das camadas populares - tendo em vista a importância da superexploração do trabalho para a manutenção dos lucros das classes dominantes -, mas na potencialização dos setores vinculados à produção de bens suntuários. No que tange ao mercado externo, o governo almejou ocupar espaços capazes de absorver a produção excedente brasileira, investindo na competitividade de sua indústria, especialmente a indústria pesada, e garantindo as condições políticas para o acesso aos referidos mercados (MARINI, 1974).

Porém, longe de constituir mera estratégia de potencialização da exportação de produtos e capitais, ou uma simples reprodução ampliada da teoria do imperialismo, o subimperialismo de Marini visava representar uma dimensão mais complexa da questão, o que levaria Luce (2014) a caracterizá-lo como etapa superior do capitalismo dependente. Do ponto de vista estritamente econômico, o subimperialismo se definiria a partir de dois eixos estruturantes: os efeitos da nova divisão internacional do trabalho, que geravam a transferência para a periferia de

\footnotetext{
${ }^{1}$ Para Marini (1974), a luta armada constituía uma forma, ou etapa, dos desdobramentos da própria luta de classes.
} 
ramos menos avançados das indústrias dos países centrais, e as próprias leis do ciclo de reprodução do capitalismo dependente, que, a partir do fenômeno da superexploração do trabalho, impunham problemas para a realização do capital, ensejando uma monopolização extremada em favor dos setores produtivos da indústria suntuária e a progressiva integração do capital nacional ao capital estrangeiro (MARINI, 1974).

Ainda que o conceito não fosse dotado apenas de dimensões econômicas, o próprio autor afirmou a preponderância dessas para a sua formulação, e inclusive para a caracterização do Brasil enquanto um país subimperialista, condição decorrente da integração de seus sistemas de produção, já evoluídos à fase do monopólio e do capital financeiro, constituindo ponto intermediário na composição orgânica do capital em nível mundial (MARINI, 1974). A dimensão política do subimperialismo aparecia, portanto, enquanto uma consequência das contradições internas concernentes ao ciclo de reprodução do capital. Assim, ao buscar o aumento da competitividade de suas empresas e o alargamento de seus mercados externos, o país subimperialista passaria a exercer uma política de cooperação antagônica com o núcleo imperialista central, que, no caso brasileiro, seria ilustrado pelos vínculos contraditórios com os Estados Unidos da América (MARINI, 1974).

Como exemplificado pelo próprio Marini (1971), iniciativas do governo brasileiro como a de desenvolver um programa nuclear nacional ilustraram as contradições da cooperação entre o Brasil, subimperialista, e os Estados Unidos da América, imperialista, caracterizando o fenômeno dialético da cooperação antagônica. Essa determinante, da cooperação antagônica, apareceria como condição sine qua non para qualificar um país capitalista dependente como subimperialista, assim como a internacionalização de sua economia para responder aos problemas internos de realização do capital. Portanto, seria a capacidade de um país dependente exercer uma política expansionista relativamente autônoma aos objetivos do centro imperialista que definiria, para além das determinantes econômicas de exportação de produtos e capitais, o fenômeno do subimperialismo. E é exatamente por isso que Marini designou, à época, apenas o Brasil enquanto país latino-americano subimperialista, ainda que México e Argentina compartilhassem de algumas de suas características (MARINI, 1971). Afinal, o subimperialismo tomaria forma não apenas 
pela exportação de capitais e produtos manufaturados para países mais frágeis, mas, também, pelas movimentações político-estratégicas que garantem sua execução e reafirmam uma espécie de dominação da potência subimperialista sobre os países de economia menos robusta. A soma das condicionantes econômicas (exportação de mercadorias e capitais) e políticas (estratégias para garantir hegemonia sobre países de menor poder relativo) resultaria na imposição de uma divisão sub-regional do trabalho, que replicaria em escala regional as assimetrias da divisão internacional do trabalho:

\begin{abstract}
Nem todos os novos subcentros econômicos que atingiam uma composição orgânica média e que passavam também à condição de exportadores de manufaturados e, em menor medida, de capitais estavam em condições de impor uma divisão sub-regional do trabalho para o proveito das suas burguesias internas. Ou seja, no conjunto do capitalismo latino-americano, apenas o Brasil tornou-se uma formação social subimperialista (LUCE, 2014, p. 52, grifos meus).
\end{abstract}

Resumidamente, o subimperialismo aparece, nos escritos de Marini, enquanto um nível hierárquico do sistema mundial e, ao mesmo tempo, uma etapa do desenvolvimento do capitalismo dependente (LUCE, 2014). O fenômeno que lhe dá impulso corresponde às próprias contradições gestadas no seio das economias dependentes de maior desenvolvimento industrial, que deparam-se com 0 aguçamento da contraposição entre suas necessidades de expansão do mercado interno, como condição para realização do capital, e o paralelo achatamento do poder aquisitivo das massas populares, subjugadas pela predominância do padrão de superexploração do trabalho. Essa contradição teria ensejado o acirramento da luta de classes, que no caso brasileiro resultou na aliança entre setores do capital estrangeiro e os estratos mais altos da burguesia brasileira para frear as reivindicações sociais e reafirmar a superexploração do trabalho, com a ditadura militar ampliando os mercados externos e potencializando setores produtivos de bens suntuários para sanar o impasse da realização de capital.

Dessa forma, Marini valeu-se das ingerências políticas da ditadura militar brasileira nos assuntos internos de países latino-americanos como exemplos de materialização do subimperialismo, tendo em vista que assegurariam, em sua ótica, a supremacia dos investimentos brasileiros naquelas nações. Com o progressivo debilitamento das ditaduras latino-americanas e a ascensão dos processos de 
redemocratização, a temática do subimperialismo foi perdendo espaço nos escritos de Marini, apesar de periodicamente rememorada. No entanto, o conceito passou a ser utilizado por outros vários autores, para além dos próprios caudatários da Teoria Marxista da Dependência, voltando a aparecer com maior frequência nas caracterizações da política externa brasileira do século XXI, dentro do contexto de pulverização dos mecanismos de integração regional na América do Sul

\section{A dimensão sul-americana da política externa brasileira à luz do subimperialismo}

Como principal mercado para as exportações de manufaturados brasileiros, a América do Sul recebeu, em 2010,18,4\% do total das exportações brasileiras, sendo $84 \%$ dos produtos exportados para a região constituídos por produtos manufaturados (COUTO, 2013). A constituição da América do Sul enquanto um mercado estratégico para o Brasil contribuiu, indubitavelmente, para que as relações com os países da região fossem alçadas às prioridades da política externa do país. Assim, a política externa brasileira visou, ao longo dos governos Lula (2003-2010), dialogar não apenas com as pretensões do novo bloco de poder governante no Brasil, mas também com aspirações historicamente presentes no desenvolvimento do Estado brasileiro e de sua diplomacia. Consequentemente, almejou aprimorar os mecanismos de funcionamento do MERCOSUL, atuando também na conformação da Comunidade Sul-Americana de Nações (CASA), e posteriormente da União de Nações SulAmericanas (UNASUL). Esse protagonismo reacendeu o ímpeto dos pesquisadores vinculados à Teoria da Marxista da Dependência, que voltaram a enfatizar a política externa brasileira para a região como de recorte subimperialista.

Mantendo as estruturas teóricas de Marini, Luce (2014) aludiu à desindustrialização brasileira como uma consequência da predominância de um novo padrão exportador de especialização produtiva, no qual a indústria de transformação, outrora ascendente, cedeu lugar às indústrias extrativistas, com as matérias-primas constituindo seu segmento dinâmico. Assim, o agronegócio e a indústria vinculada ao extrativismo mineral seriam os principais motores da busca por diversificação do mercado externo, dando sentido à estratégia da política externa dos governos Lula. Ao atualizar a aplicação do conceito de Marini, foi ainda mais longe que o patrono dos 
dependentistas marxistas, designando outras potências regionais ascendentes como subimperialistas e mencionando até mesmo os arranjos multilaterais de cooperação sul-sul como instrumentos desses projetos.

Assim, teceu observações acerca das relações bilaterais do Brasil com alguns países sul-americanos, ressaltando as assimetrias geradas a partir dos processos de internacionalização das empresas brasileiras. No caso boliviano, destacou as distorções causadas pelos investimentos da Petrobras no país, que estaria se aproveitando das privatizações de empresas para consolidar seus interesses na cadeia produtiva do gás, revertendo seus excedentes econômicos em lucros, ao invés de utilizá-los em prol da população boliviana (LUCE, 2007). Também destacou as atuações das empresas brasileiras no Uruguai, no Peru, no Equador, na Argentina e no Paraguai, sempre submetido ao princípio - alinhado com Marini - de que os investimentos em questão reproduziam a dissociação entre os rumos da produção de mercadorias e as necessidades objetivas dos povos dessas nações. No caso, a priorização brasileira pela busca de excedentes no exterior estaria pautada na prevalência dessa mesma contradição entre as esferas produtivas e as demandas populacionais, no interior de sua própria economia dependente (LUCE, 2014).

Avançando no seu raciocínio, Luce (2011) dissertou, também, sobre as finalidades dos processos de integração regional. Para o autor, tanto o fomento da Iniciativa para a Integração Regional Sul-Americana (IIRSA) quanto a edificação da CASA e da UNASUL seriam elementos complementares da estratégia subimperialista brasileira, com a primeira representando sua dimensão de integração de infraestrutura, ao passo que as segundas seriam instrumentos úteis ao equacionamento político de possíveis obstruções às suas pretensões hegemônicas. Além disso, o próprio modelo da IIRSA acirraria o padrão de especialização produtiva da região, inclusive do Brasil, visando atender uma divisão internacional do trabalho contraditória com as necessidades objetivas do desenvolvimento da nação, que assistiria ao fortalecimento de sua burguesia ao mesmo tempo em que negaria às classes subalternas suas condições mais essenciais de vida e trabalho (LUCE, 2014).

Fontes (2013) potencializou essa percepção, atribuindo à inserção internacional brasileira a caracterização de capital-imperialista. Para a autora, o desenvolvimento capitalista do Brasil levou-o a integrar o grupo de países capital- 
imperialistas do sistema internacional, ainda que mantendo um nível secundário em relação às nações mais desenvolvidas, como os Estados Unidos da América. Novamente a exportação de capitais e mercadorias brasileiras para o exterior, bem como a internacionalização das empresas, aparecem como as comprovações do suposto comportamento predatório brasileiro, agora capital-imperialista, com o adendo de, na versão da autora, até o Canadá ser inserido como suposta vítima dessas políticas (FONTES, 2013).

Zibechi (2013) indicou a necessária atualização do conceito de Marini, de forma a compatibilizá-lo com a inserção internacional brasileira no século XXI. Segundo o autor, na atual quadra histórica as elites dominantes do Brasil ampliaram suas margens de manobra e, num conluio entre os militares e a burguesia brasileira, construíram uma estratégia de poder capaz de alçar a nação à condição de potência. Nessa estratégia, os vizinhos sul-americanos seriam vistos como o pátio traseiro do país, com os quais as relações se mantêm extremamente assimétricas. $O$ autor sugeriu que o próprio conceito de imperialismo talvez melhor se encaixasse, hoje, à atuação brasileira do que o de subimperialismo.

Dando substância à sua tese, Zibechi produziu um amplo e exaustivo levantamento de dados acerca dos processos de exportação de capitais e de internacionalização das empresas brasileiras. Todo esse processo estaria articulado com uma ampla estratégia das elites brasileiras de construção de um novo complexo industrial-militar, inspirada na Estratégia Nacional de Defesa (END). Analisando os casos concretos, o autor destacou eventos como a presença dos brasiguaios no Paraguai e as características predatórias e assimétricas com as quais o Brasil estabelece o repartimento dos lucros de Itaipu com o vizinho, a presença ostensiva da Petrobras e de fazendeiros brasileiros na Bolívia, a inserção incisiva da Odebrecht e da Petrobras no Equador, e, logicamente, os respectivos conflitos políticos e sociais decorrentes desses fenômenos. Assim, convocou os países e povos da região para frear o avanço imperialista brasileiro (ZIBECHI, 2013).

Ainda que guardando semelhanças com os textos dependentistas, as críticas de Zibechi (2013) se alinham com uma perspectiva adicional de contraposição à própria noção de desenvolvimento econômico e às práticas extrativistas que lhe dão sustentação. Por isso o questionamento a empreendimentos brasileiros sem maiores 
impactos diretos para os países vizinhos - caso de Belo Monte -, afinal estende a polêmica para o próprio modelo de exploração de recursos naturais utilizado mundo afora, seja por nações capitalistas ou até mesmo socialistas. Apesar de distinta das proposições originais de Marini e dos demais autores vinculados com a TMD, essa aproximação com teses de matriz ambientalista ou pós-colonial ecoa, supreendentemente, sobre o conjunto dos trabalhos dependentistas supostamente marxistas que hoje questionam os empreendimentos da IIRSA.

López e Lima (2017) também viram nas relações bilaterais sul-americanas a reprodução do comportamento subimperialista brasileiro. Para tanto, descreveram o padrão das relações entre Brasil e Bolívia enquanto um flagrante exemplo de execução dos múltiplos interesses da burguesia brasileira, que, por detrás de um projeto neodesenvolvimentista e uma política externa de Brasil Potência, busca forjar a perpetuação de sua hegemonia na região. No caso das relações com o Paraguai, destacam, assim como Zibechi, os supostos prejuízos materializados pelas assimetrias da exploração conjunta da hidrelétrica de Itaipu, que serviria enquanto mero instrumento de fornecimento de energia barata para o Brasil, às custas dos paraguaios.

Com respeito aos mecanismos de integração regional apoiados pela política externa brasileira, Carcanholo e Saludjian (2013) destacaram o perfil liberal das suas dimensões econômicas, com a tendência de aprofundarem a especialização produtiva da América do Sul, especialmente devido ao panorama de progressiva penetração chinesa nas relações comerciais regionais - que contribuiria, em suas visões, para a dinâmica do empobrecimento tecnológico das exportações dos países sulamericanos. Ao analisar a IIRSA, Borón (2013) endossou essa leitura relativa à consolidação de um padrão de especialização produtiva, mas designando-a como caudatária dos interesses estadunidenses na região, e alinhada às pretensões de reavivamento da Área de Livre Comércio das Américas (ALCA).

Em termos gerais, nem todos os autores que caracterizaram a dimensão sulamericana da política externa brasileira dos governos Lula como subimperialista utilizaram, em seus embasamentos, o conceito proveniente de Ruy Mauro Marini e da Teoria Marxista da Dependência. Virgínia Fontes, por exemplo, tachou o Brasil de capital-imperialista. Zibechi, ainda que valendo-se de parte do aporte teórico de 
Marini, aproximou sua tese do rechaço às políticas extrativistas de desenvolvimento, alinhando-se, de certa forma, às críticas de Gudynas (2012) ao neoextrativismo.

No entanto, todas essas teorias e conceitos - desde o subimperialismo da TMD até a crítica mais abrangente de Zibechi - apontaram o processo de internacionalização de empresas e exportação de mercadorias e capitais brasileiros enquanto eixos estruturantes das relações assimétricas estabelecidas com países de menor envergadura político-econômica, tanto da América Latina quanto da África. A potencialização da presença brasileira nas respectivas economias desses países estaria ensejando, de forma latente, uma dominação política de feição subimperialista, imperialista ou capital-imperialista, que reproduziria uma divisão sub-regional do trabalho responsável por perpetuar relações de dominação típicas do sistema internacional capitalista. Nas próximas seções, essas interpretações serão analisadas à luz das realidades políticas e econômicas que visam elucidar, deparando-se com questionamentos acerca do conjunto estruturante de suas proposições.

\section{A inversão do desenvolvimento desigual e suas consequências políticas}

Verificados os fundamentos da compreensão da teoria leninista do imperialismo pelos próprios formuladores do conceito de subimperialismo, se torna mais simples visualizar as razões de sua utilização para enquadrar as movimentações da política externa brasileira dos governos Lula. Embasados numa visão hierárquica do sistema internacional, que contrapõe países do capitalismo central aos países dependentes, os dependentistas buscaram nas potências médias capazes de propor uma divisão sub-regional do trabalho o exemplo perfeito para o encaixe de suas caracterizações. Verificando o protagonismo brasileiro nas formulações dos processos de integração regional na América do Sul, naturalmente resgataram a utilização do conceito e utilizaram-no para revelar os supostos desejos predatórios do Brasil por detrás de suas agendas de cooperação.

Retomando o conceito de subimperialismo, vimos que afirma a exportação de produtos e capitais enquanto decorrência da escassez de mercado interno, gerada pelos mecanismos de superexploração do trabalho que reafirmam o desnivelamento dos elementos norteadores do aparato produtivo nacional - voltado para a acumulação 
de capital das elites, e não para sanar as necessidades imediatas da população. Todas essas condições apenas resultam em parte de uma política subimperialista caso esse mesmo país exerça uma cooperação antagônica diante dos países capitalistas centrais, com relativa autonomia em sua política externa, voltada para assegurar a hegemonia de seus investimentos perante as nações mais frágeis às quais exporta produtos e capitais. Como exposto anteriormente, existem outros elementos também condizentes com esse fenômeno - casos da financeirização da economia dependente, dos processos de fusão e monopolização de capitais, além da constante penetração do capital estrangeiro imperialista na própria economia dependente do país subimperialista. Ainda assim, esse esquema satisfaz, em linhas gerais, as principais características da aplicação do conceito de subimperialismo, e será por demais útil para analisar até que ponto ele converge com as movimentações da inserção internacional brasileira no alvorecer do século XXI.

Ao alegar, enquanto hipótese, as limitações da utilização do conceito de subimperialismo para explicar a política externa brasileira do século XXI, o presente artigo não o faz apenas por encontrar divergências entre sua aplicação e os acontecimentos do período, mas também por verificar suas discrepâncias perante as afirmações da tradição teórica que advoga reproduzir. Ainda que não seja uma mera reprodução do conceito de imperialismo exposto por Lenin, o subimperialismo surgiu enquanto uma proposta de Marini para suprir lacunas da abordagem leninista, corroborando suas principais estruturas e acrescentando as especificidades afins ao chamado capitalismo dependente. No entanto, mesmo fixando a teoria leninista do imperialismo enquanto ponto de partida, os dependentistas invertem alguns de seus principais enunciados:

Contrariamente à interpretação que acabou predominando nos enfoques da chamada teoria da dependência latino-americana nos anos 1960 e 1970, o conceito de 'desenvolvimento desigual' formulado por Lênin não apontava para o contínuo aprofundamento das assimetrias entre centro e periferia na economia capitalista mundial - o que Gunder Frank chamava de 'desenvolvimento do subdesenvolvimento' -, mas precisamente para o seu contrário: a tendência estrutural à erosão de poder do centro dominante face à ascensão de novos pólos de maior dinamismo econômico em áreas de desenvolvimento capitalista mais tardio no próprio centro ou na periferia do sistema (FERNANDES, 2017, p. 58).

Ao inverterem o sentido do processo de exportação de capitais e seus respectivos efeitos, os dependentistas tornam esse fenômeno a própria razão da 
hierarquização das nações no sistema internacional. Basicamente, aqueles com maior capacidade de exportar mercadorias de alto valor agregado e capitais para a periferia comporiam o núcleo imperialista da economia mundial, enquanto as potências médias capazes de impor uma divisão sub-regional do trabalho - também baseada na exportação de capitais e produtos de maior valor agregado - constituiriam o segundo grupo, de países dependentes com status subimperialista, exercendo a cooperação antagônica com os centros imperialistas.

Mas, contrariamente ao alegado pelos dependentistas, Lenin (2011) apontou o efeito imperialista do desenvolvimento desigual enquanto motor das tensões entre os Estados nacionais, tendo em vista a tendência do capital em migrar das economias mais avançadas e financeirizadas para a periferia. Nessa, garantiria maiores taxas de lucro, acarretando o desenvolvimento das forças produtivas e relações de produção capitalistas, gerando novas contradições sociais e, a depender dos resultados dessas, podendo levar a periferia a aspirar ser centro, gerando as guerras de disputa por hegemonia. Resumidamente, de forma progressiva os países capitalistas centrais seriam consumidos pela hegemonia do capital financeiro em suas economias, que por uma lógica rentista e parasitária lucraria a partir da especulação, sustentada por excedentes extraídos de atividades produtivas realizadas fora do centro (FERNANDES, 2017). Longe de significar uma completa estagnação das economias periféricas, as contradições do imperialismo, fase superior do capitalismo, também abririam margens para o desenvolvimento de novos polos dinâmicos, a depender da forma como se inserissem no conjunto dessa intrincada rede de relações:

Quando Lenin destaca a formação dos monopólios, fusões de capital
industrial e bancário, exportações de capitais e partilha territorial entre as
potências, está abordando características gerais da fase madura do
capitalismo (imperialismo). Mas, da mesma forma, o autor reconhecia
também o papel do financiamento e da apropriação de tecnologias no
desenvolvimento da economia moderna. Nessa, o desenvolvimento desigual
do capitalismo combina forças centrífugas (concentração) e centrípetas
(expansão/difusão) que alteram o balanço de poder no mundo, em processos
de ascensão e declínio de polos econômicos. Em suma, um país periférico,
apesar da dependência, pode 'queimar etapas' no processo de
desenvolvimento, explorando o conjunto de interações entre o nacional e o
internacional (PAUTASSO, 2013, p. 76).

A compreensão dependentista designa a exportação de capitais pelos países centrais como propulsora do subdesenvolvimento - ou da dependência - dos países periféricos. Politicamente, Marini e seus seguidores sempre defenderam a 
mobilização das massas populares para a execução de uma revolução como principal alternativa para a resolução os principais problemas nacionais. Aderem a essa alternativa pois entendem que o desenvolvimento capitalista na periferia se sustenta pela superexploração da força de trabalho, fenômeno reprodutor do subconsumo, elemento necessário, apesar de encolher o mercado, para garantir os lucros de uma burguesia nacional subserviente ao grande capital internacional. Só uma revolução social garantiria a quebra desse ciclo, tendo em vista que a burguesia jamais promoveria, por exemplo, políticas de valorização da remuneração da força de trabalho ou uma ampla reforma agrária que afetassem os próprios fundamentos de sua sobrevivência.

Fatalmente, esse entendimento levou os dependentistas a verem nas alianças policlassistas o problema em si das estratégias dos partidos de esquerda, afinal não existiria possibilidade de desenvolvimento dentro das leis de reprodução do capitalismo dependente. Apenas a revolução social, a ser dirigida pelas forças populares contra as burguesias nacional e internacional garantiria 0 desenvolvimento ${ }^{2}$. Isso impediu que, às vésperas dos golpes militares no Brasil, em 1964, e no Chile, em 1973, os agrupamentos políticos de Marini, respectivamente a ORM-POLOP e o MIR, percebessem a centralidade da aliança com os setores centristas e burgueses - respectivamente ilustrados pelo Partido Social Democrático (PSD) e a Democracia Cristã - para manter as bases de sustentação dos governos de João Goulart e Salvador Allende. Na contramão, defendiam o rompimento imediato dos vínculos com esses setores, contribuindo para o sucesso da estratégia subversiva dos opositores:

Com a radicalização impulsada pelos militantes do MIR, da esquerda do PS e de outras tendências radicais, gritando nas duas 'crear, crear, poder popular' e 'trabajadores al poder', configurou-se no Chile uma situação muito similar à que precedeu o levantamento do general Francisco Franco, na Espanha, contra o governo republicano, em 1936. Eles agiam da mesma forma que os militantes do Partido Socialista Operário Espanhol (PSOE), que clamavam pela formação de um governo proletário e de um exército do povo, com bandeiras vermelhas e retratos de Lenin, Stalin e Francisco Largo Caballero. Imaginavam Madri como se fosse Petrogrado, às vésperas da insurreição bolchevique, em 1917. Porém, nem na Espanha, em 1936, nem no Chile, em 1973, o Exército estava desintegrado, como ocorrera na Rússia, cujas tropas, desmoralizadas e desgastadas pelas derrotas na guerra contra a Alemanha, se haviam amotinado e terminaram por aderir e sustentar a revolução liderada por Vladimir Lenin e Leon Trotsky. Ao mesmo tempo, o

\footnotetext{
2 Uma crítica introdutória aos fundamentos dessa estratégia foi esboçada em Nogara (2019b).
} 
acelerado processo de expropriações, ocupações, requisições e intervenções, atingindo tanto empresas industriais quanto estabelecimentos agrícolas, concorreu para desorganizar a economia, diminuir a produtividade e agravar o desabastecimento e a inflação, dado que os trabalhadores não estavam treinados para administrar as empresas e manejar a contabilidade. Tais problemas gerados pela estatização abrupta de vários setores produtivos favoreceram a aplicação da fórmula para o caos, implementada pela CIA, em meio às greves gerais e aos atentados terroristas que ela encorajava e financiava, enquanto a guerra psicológica, aviventando o espectro do comunismo, empurrava mais e mais as classes médias para oposição e com elas a oficialidade das Forças Armadas (BANDEIRA, 2008, p. 592, grifos meus).

Não por acaso, o Cabo Anselmo - conhecido agente vinculado à ClA e infiltrado nos movimentos esquerdistas brasileiros - dirigiu, em março de 1964, uma revolta dos marinheiros em favor da radicalização das reformas de base. Afinal, a estratégia dos golpistas era justamente essa: forjar uma radicalização da ala esquerda dos governistas para que os setores centristas, tanto parlamentares quanto militares, deixassem de dar sustentação ao governo. No Chile não foi diferente, tendo em vista o peso que possuía a Democracia Cristã não apenas no parlamento - que acabou por obstruir toda e qualquer movimentação política de Allende -, mas também sobre os posicionamentos da alta patente militar.

Para além de suas implicações concernentes às estratégias políticas de movimentos e partidos marxistas, a visão de mundo acoplada ao paradigma dependentista também fincou raízes, como já ilustrado, nas análises acerca do padrão de inserção internacional dos países latino-americanos. Tecendo observações sobre as estruturas que regem as relações assimétricas da ordem global, buscou elucidar, a partir de concepções marxistas, o funcionamento e a dinâmica da ascensão e estagnação das distintas nações no sistema internacional. Replicando os moldes de sua compreensão sobre o desenvolvimento desigual, também fortaleceu posições às quais visava discursivamente antagonizar, como veremos a seguir.

\section{Brasil, América do Sul e desenvolvimento periférico: o naufrágio do determinismo}

Como já destacado, grande parte das exportações de produtos brasileiros de maior valor agregado se concentra em direção aos países da América do Sul. Ainda assim, há uma grande distância entre constatar a importância desses mercados para 
a exportação de produtos brasileiros e indicar esse fenômeno como parte de uma política subimperialista, ou de entrave ao desenvolvimento das economias vizinhas. Afinal, as cobranças dos países vizinhos ao Brasil são exatamente por esse hesitar em assumir o papel de paymaster do processo de integração, e não de estar "invadindo" suas economias com investimentos e produtos manufaturados. Ao fortalecer, via BNDES, os processos de integração de infraestrutura na América do Sul, o Brasil visou atender, em parte, essas demandas, em muito baseadas no fato de o Brasil ter logrado constantes superávits comerciais anuais com quase todos os países sul-americanos à época, com exceção constante da Bolívia e conjuntural de outros países (COUTO, 2013).

Curiosamente, questionamentos ao perfil de integração sul-americana proposto pelo Brasil no período vêm exatamente de um dos países com menor dependência relativa à economia brasileira, a Venezuela ${ }^{3}$. Poderia se afirmar, intuitivamente, que essa menor vinculação com o Brasil seria uma variável permissiva ao radicalismo retórico inerente aos governos chavistas, especialmente diante das iniciativas brasileiras. No entanto, essa opção dificilmente se alinharia a outra realidade: a persistente tensão nas relações entre a Venezuela e os Estados Unidos da América, num contexto em que a baixa diversificação da economia venezuelana empurra sua pauta exportadora para relativa dependência das importações petrolíferas estadunidenses. Logo, a explicação do antagonismo poderia migrar, novamente, para o polo oposto: as tensões são fruto do antagonismo chavista à dependência perante os EUA. Mas, outra vez, a análise encontraria dilemas, como os de elucidar a contemporânea postura do também 'bolivariano' Evo Morales, que mesmo após a posse do politicamente antagônico Jair Bolsonaro, no Brasil, manteve esforços para evitar qualquer deterioração das relações bolivianas com o país ${ }^{4}$. As

\footnotetext{
${ }^{3}$ Durante os governos Lula, foram perceptíveis as distintas concepções de Brasil e Venezuela acerca dos rumos a serem adotados pela integração sul-americana. Ainda que estabelecendo alianças táticas nos processos de negociação da ALCA, na conformação da CASA e da UNASUL, e na incorporação venezuelana ao Mercosul, essas diferenças se fizeram sentir na elaboração das dinâmicas do Banco do Sul, do Conselho de Defesa Sul-Americano (CDS), nas questões vinculadas à integração de infraestrutura e no perfil a ser adotado pelos países da região frente aos grandes organismos internacionais e à política externa dos Estados Unidos da América.

${ }^{4}$ Às vésperas da posse de Jair Bolsonaro, Evo Morales fez questão de ressaltar que Brasil e Bolívia atuam como sócios estratégicos, mirando o mesmo horizonte da "Pátria Grande" (G1, "Evo Morales fala sobre a posse de Bolsonaro e diz que Brasil e Bolívia "miram o mesmo horizonte", G1, Janeiro 01 , 2019, acesso em Abril 14, 2019).
} 
limitações dessas simplificações são evidentes, e respondem às insuficiências de se tentar explicar o comportamento dos Estados nacionais e suas lideranças como mero reflexo das assimetrias da divisão internacional do trabalho. Afinal, fosse essa divisão um processo estático de simples reafirmação de hegemonia, o que explicaria os ciclos de ascensão e queda das potências globais e regionais?

Entre as décadas de 1960 e 1980, a organização de uma divisão sub-regional do trabalho que orbitava a economia japonesa serviu como mola propulsora do desenvolvimento de países com projetos de inserção internacional assertiva, como a China comunista e os próprios Tigres Asiáticos. Nos Tigres, o Estado de Desenvolvimento Capitalista esteve embasado em regimes políticos ditatoriais, nos quais o aparato estatal planejava os aspectos essenciais da economia e intervinha ativamente nela, estatizando ou controlando indiretamente vários setores, especialmente o financeiro (VISENTINI, 2012). A receita obtida com as exportações foi acumulada para fomentar a industrialização, e o mercado interno era fortemente protegido, de forma a evitar a perda de divisas. O Estado, associado às empresas privadas, investiu maciçamente em tecnologia e formação de mão-de-obra especializada, e as empresas dos ramos estratégicos da economia foram agrupadas em conglomerados empresariais de caráter fortemente oligopolista, denominados na Coreia do Sul de Chaebol. Cúmulo da ironia, os governos direitistas de Taipé e Seul realizaram reformas agrárias radicais, visando modernizar a agricultura e acumular capital, tomando como referências algumas políticas de seus rivais comunistas (VISENTINI, 2012). Com o ingresso do Japão na etapa de desenvolvimento vinculada com os progressos científicos da III Revolução Industrial - concentrando sua produção nas áreas de informática, automobilísticas, robóticas e de setores de tecnologia de ponta -, as economias do seu entorno também lograram ganhos absolutos em seus respectivos projetos de desenvolvimento:

Os Tigres, tanto por esforço próprio como em decorrência da nova conjuntura, desenvolviam a segunda fase japonesa, com o aço, produção naval, automóveis, motores, produtos elétricos e outros de tecnologia mais avançada. A China, por sua vez, associa-se a este movimento, recebendo investimentos e plantas industriais japonesas e ocidentais, desempenhando um papel econômico semelhante ao que fora o dos Tigres, explorando suas vantagens comparativas e competindo em alguns campos com eles. A diferença era que a China dispunha de poder militar, dimensão territorial e populacional e autonomia (inclusive com seu ingresso no CS da ONU), 
podendo dar a seu projeto uma dimensão qualitativamente mais relevante que a dos Tigres (VISENTINI, 2012, p. 65).

Hoje, parte do entorno regional chinês tem suas economias orbitando a da própria China, que cumpre papel semelhante ao que outrora foi da economia japonesa na região. Ainda que a pauta das exportações de muitos desses estejam embasadas em produtos de menor conteúdo tecnológico que aqueles exportados pelos chineses, permitem a eles um superávit que, se utilizado coerentemente dentro de uma estratégia nacional de desenvolvimento, pode render, futuramente, a alteração do próprio conteúdo destas relações comerciais. Relação semelhante pode ser imputada às assimetrias entre as pautas de exportação dos países sul-americanos, bem como entre Brasil e China:

Cabe, ademais, ressaltar que a desindustrialização e reprimarização não podem ser reduzidas a faces de uma mesma moeda: o crescimento da exportação de minérios e produtos agrícolas em atendimento à demanda chinesa em nada fere o core do conceito; poderia ser vista como oportunidade e não como ameaça, caso fosse inserida em um projeto ou estratégia de desenvolvimento. A reprimarização da pauta de exportações, assim, não necessariamente significa desindustrialização, mesmo porque o Brasil possui mercado interno robusto, e o superavit externo gerado pela exportação de commodities poderia, em eventual projeto, tornar-se variável relevante para alavancar o crescimento de setores de alta tecnologia ou distribuição de renda mais equânime (FONSECA, 2015, p. 50).

Essa breve recapitulação dos processos de desenvolvimento asiáticos evidencia, portanto, as contradições do argumento de que uma eventual divisão subregional do trabalho na América do Sul serviria simplesmente para reafirmar relações de dominação. Caso os projetos de desenvolvimento das nações fossem eternamente determinados pelas relações econômicas assimétricas em que estão inseridas, não haveria razão para a ocorrências de transformações no perfil das disputas no sistema internacional, afinal não existiriam margens para a política, a estratégia e o planejamento dirigirem as forças econômicas. Assim, inexplicável seria o processo que levou à reversão do padrão das relações entre Brasil e China ${ }^{5}$, que na década de

\footnotetext{
${ }^{5}$ Quando se tratando de China, é inevitável destacar o papel das distintas gerações de lideranças do Partido Comunista da China (PCCh) na composição de estratégias que, adequadas à realidade de uma ordem internacional em constante mutação, permitiram ao país avançar do processo de reconstrução nacional, iniciado em 1949, para uma etapa qualitativamente distinta do desenvolvimento do país, com implicações cruciais para a transição sistêmica em curso. Para mais detalhes sobre a interação entre
} 
1980 verificava a venda de petróleo chinês ao Brasil, e a compra, por parte dos chineses, de produtos de maior conteúdo tecnológico com fabricação brasileira ${ }^{6}$. Ao tomarem as assimetrias das relações comerciais e de investimentos entre as nações como conteúdo em si da caracterização de suas posições no sistema internacional, a teoria da dependência ossifica o status quo hierárquico da ordem internacional, entendido como uma reprodução ampliada das leis de reprodução do capital no centro e na periferia?.

Como praticamente toda a descrição do fenômeno subimperialista por Marini se concentrava nas razões do porquê de o padrão de reprodução do capital ensejar sua realização para além das fronteiras nacionais - pela via da exportação de capitais e mercadorias -, pouca atenção dispensou para o que caracterizaria, politicamente, a relação entre os ditos países subimperialistas e aqueles imersos nas suas divisões sub-regionais do trabalho. Quando o fazia, aludia às intervenções do governo militar brasileiro nos assuntos políticos internos dos países vizinhos, guiadas pela lógica das fronteiras ideológicas e alinhadas aos interesses estadunidenses de combate ao comunismo e às esquerdas, no contexto da Guerra Fria.

No entanto, em pleno século XXI, as relações estabelecidas pelo Brasil com os países de seu entorno estratégico passam longe de aludir ao grau de intervenção utilizado pela ditadura militar ${ }^{8}$. De qualquer forma, nos estudos de caso elaborados pelos dependentistas para referendar a existência do dito subimperialismo brasileiro, são utilizados os processos de internacionalização das empresas brasileiras e a defesa destas pelo Estado nacional como exemplos pretensamente irrefutáveis de sua comprovação. Nesse sentido, há de se perceber que praticamente nenhum Estado nacional mundo afora costuma se omitir em situações de defesa da atuação das suas empresas no exterior. Assim como o Brasil relutou em ceder os ativos da Petrobras até então logrados em solo boliviano, a Bolívia também relutaria em aceitar

o projeto de desenvolvimento nacional chinês e as disputas sistêmicas, ver Pautasso (2019) e Pautasso et al (2019).

${ }^{6}$ Para mais detalhes sobre a reversão do padrão da pauta comercial de Brasil e China, ver Oliveira (2012).

${ }^{7}$ Esse argumento foi introduzido em Nogara (2019b).

${ }^{8}$ Inclusive, a UNASUL surgiu enquanto fórum de incentivo para a concertação política conjunta das questões afins à América do Sul, e a própria inserção das cláusulas democráticas nos instrumentos de integração regional rechaça eventuais intervenções diretas nos assuntos internos dos demais países. 
eventual rompimento unilateral dos mecanismos que regem o funcionamento do GasBol.

No conjunto das críticas dependentistas, o Brasil foi caracterizado como o único país subimperialista da América do Sul. Nesse panorama, cabe assinalar que, quase ao final dos governos Lula, o Brasil sequer constava na lista dos cinco maiores investidores estrangeiros de qualquer país da região, com exceção do Uruguai ${ }^{9}$. A Bolívia, um dos países utilizados pela bibliografia dependentista como exemplo de vítimas do subimperialismo brasileiro, recebeu, no período, maiores investimentos diretos da Colômbia do que do próprio Brasil (COUTO, 2013). Da mesma forma, a lógica de que a política externa brasileira seria determinada pelos anseios da burguesia, ávida por ocupar mercados sul-americanos, não guarda similitude com a realidade, afinal, foi o Estado que estabeleceu mecanismos de incentivo para a burguesia nacional fortalecer seus investimentos nos países vizinhos, e não o contrário:

\begin{abstract}
A iniciativa privada não segue a priorização da agenda diplomática. O fôlego e as apostas empresariais vão além das escolhas políticas do Estado. A América do Sul, apesar de prioridade explícita da diplomacia brasileira, não exerce a mesma força de atração aos agentes econômicos nacionais, que parecem não seguir fielmente a indução ou orientação estatal, nos moldes designados pelo Estado Logístico. (...) A expansão das exportações para a região, que segue o ritmo do aumento das vendas brasileiras para o mundo como um todo - visto que a América do Sul não aumenta sua fatia nas exportações do país - não é compensado pelo ânimo importador ou pelo fluxo de investimento externo que sai do país (COUTO, 2013, p. 200).
\end{abstract}

Berringer (2013) apontou que as orientações da política externa brasileira ao longo dos governos petistas refletiram a ascensão da burguesia interna no bloco de poder governante, mas que, ainda assim, foram evidentes certas discordâncias entre as diretrizes implementadas e os interesses dessa fração de classe. Quanto à América do Sul, se por um lado o governo obteve apoio na maioria dos seus esforços em prol da potencialização dos mecanismos de integração regional, por outro enfrentou

\footnotetext{
${ }^{9}$ Entre 1999 e 2009, segundo dados da CEPAL, apesar de o Brasil ter sido o país sul-americano com maior volume de investimento direto no exterior nos últimos anos, não constou na lista dos cinco países com maiores investimentos na América do Sul. Apenas em relação ao Uruguai o Brasil constava entre os cinco maiores investidores, onde aparece inclusive atrás da Argentina. O Chile, por sua vez, apareceu entre os cinco maiores investidores na Argentina e no Peru, principal destino de seus investimentos. A Colômbia, por sua vez, constou na lista dos maiores investidores de Bolívia e Venezuela na década de 2000. (COUTO, 2013)
} 
questionamentos desses setores frentes a acontecimentos como o ingresso da Venezuela no Mercosul, o imbróglio da Petrobras na Bolívia e a revisão do Tratado de Itaipu com o Paraguai (BERRINGER, 2017).

Por outro lado, as análises de Couto (2013) reiteram que essas divergências se materializaram para além de questões pontuais, tangenciando o fato de as prioridades comerciais e de investimento da burguesia nacional estarem voltadas para outros cenários, que não o sul-americano. Nesse sentido, teria sido o componente de uma política de Estado que determinou a maior presença de agentes econômicos brasileiros nos países vizinhos, e não o contrário, como advogam os dependentistas. Diante do atual cenário de retração da inserção internacional brasileira, as teses que creditam a estratégia da diplomacia brasileira ao simples reflexo dos interesses econômicos da burguesia nacional encontram ainda mais dificuldades para se afirmar:

\begin{abstract}
A aplicação da tese do subimperialismo enfrenta óbices factuais como irrelevância dos IED apoiados pelo Estado no conjunto de investimentos no exterior, ausência de política de apoio à internacionalização durante a maior parte dos ciclos de expansão das empresas brasileiras no exterior, desmantelamento do recente arranjo institucional (o BNDES fechou todos os escritórios no exterior e paralisou todos os desembolsos da Finem internacionalização e Exim para obras em outros países), criado para estimular a internacionalização, perda relativa gradativa de importância do Brasil nos fluxos de IED na América Latina e ampliação percentual de Chile e Colômbia. (SANTOS, 2018, p. 133)
\end{abstract}

Diante dessas contradições, uma série de questionamentos aparece sem resposta. Da forma como propugnava Marini, a ocorrência de uma revolução socialista em um país como o Brasil tendia a modificar as condições objetivas para o estabelecimento de um processo acelerado de industrialização e desenvolvimento. Tomando essa possibilidade como real, pode-se induzir que, provavelmente, os produtos de maior valor agregado seguiriam sendo direcionados aos mercados de países de menor capacidade produtiva. Nesse caso, o Brasil socialista seguiria sendo caracterizado como subimperialista?

A existência de assimetrias na ordem internacional não é uma exclusividade do modo de produção capitalista, o mercado em si é caracterizado por relações assimétricas, e não deixaria de existir caso o Brasil fosse tomado por uma revolução socialista, assim como a URSS não deixou de interagir com o mercado, em seu sentido amplo, após a revolução que levou os bolcheviques ao poder. Fossem os processos de industrialização e de distribuição de renda uma mera expressão de 
vontade político-ideológica dos governantes, jamais teriam existido racionamentos em países socialistas, e tampouco Lenin recorreria à NEP como recurso tático para fortalecer a URSS nos anos subsequentes à revolução. A confusão, e quase fusão, operada pelos dependentistas, ao analisarem tanto mercado e capitalismo quanto assimetrias e dominação, demarca dificuldades para a elucidação dos movimentos de ascensão e queda das potências no grande tabuleiro internacional. Assim - alinhandose às tradições trotskistas - tendem a recorrer a subterfúgios como o da traição dos ideais ${ }^{10}$ para analisar a realidade de países socialistas que, ao depararem-se com a realidade concreta, praticaram estratégias heterodoxas, não prescritas em compreensões metafísicas acerca do que seria o socialismo ${ }^{11}$.

Ao enfatizar a necessidade de evolução dos instrumentos de integração sulamericana, - em suas dimensões política e econômica - o Brasil o faz, sem dúvidas, em consonância com seus interesses nacionais, tanto de segurança e defesa quanto de garantia de mercados para a exportação de seus produtos e capitais. No entanto, o cálculo político dos países vizinhos não se faz com outro procedimento senão o mesmo do Brasil, com adaptações às suas respectivas realidades. A assimetria das capacidades política e econômica não é uma variável estática, e foi por essa razão que não apenas as proposições brasileiras de integração, mas também outras, como da ALBA-TCP e da Aliança do Pacífico, apareceram com força no alvorecer do século $\mathrm{XXI}$. Ao invés de constituírem um problema, as maiores capacidades propositivas do Brasil surgiram como elemento com o qual estes países adjacentes puderam manobrar em seu próprio proveito, como fizeram Uruguai e Paraguai para garantir a instituição do FOCEM, no âmbito do MERCOSUL, o Paraguai, novamente, no processo de renegociação de Itaipu, e a Bolívia no imbróglio envolvendo a Petrobras.

Especificamente na gestão de Itaipu e do Gasbol, as relações do Brasil com Paraguai e Bolívia se caracterizam muito mais por uma situação de interdependência

\footnotetext{
${ }^{10}$ Losurdo (2004) designou esse comportamento dos marxistas contemporâneos como autofóbico, ao optar pelo simples refúgio no idealismo da "traição aos ideais" ao invés de reivindicar e debater as experiências históricas embasadas nos ideais socialistas. Para uma sistematização dessa concepção de Losurdo, ver Nogara (2019a).

11 Halliday (1999) destacou que as tendências que delimitam a formulação da política externa de Estados revolucionários não são embasadas em problemáticas meramente ideológicas, respondendo também às suas necessidades materiais imediatas e às estruturas profundas da inserção internacional do país, com as quais interagem diretamente quando da tentativa de operar bruscas inflexões em seus rumos.
} 
do que de submissão de um país ao outro. Afinal, nesses meios foi criada igual dependência para a economia brasileira quanto ao fornecimento de eletricidade e gás pelos vizinhos, eventualidade que nada tem de imaginária, como se viu em vários impasses na negociação do preço da energia (RICUPERO, 2017). Criar a imagem de um gigante brasileiro subimperialista, ou até mesmo imperialista, engolindo seus pequenos e indefesos vizinhos não constitui uma caracterização fidedigna da realidade, mas um retrato que guarda pouca ou nenhuma semelhança com o conteúdo dos processos decisórios da política internacional.

A circulação e potencialização desse conceito nos meios acadêmicos e militantes acaba repercutindo sobre as dimensões do debate teórico e político concernentes às suas temáticas. Teoricamente, ao proporem uma atualização do pensamento marxista e leninista para a compreensão das relações internacionais, a TMD e o conceito de subimperialismo sustentam um estruturalismo determinista, invertendo o sentido de conceitos-chave como o de desenvolvimento desigual, e afetando a própria capacidade dos marxistas alinharem suas perspectivas aos acontecimentos correntes nas relações internacionais. Politicamente, induzem os movimentos de esquerda dos países periféricos a adotarem orientações antagônicas às alianças policlassistas, gerando uma tendência ao isolamento político ${ }^{12}$ e ao distanciamento dos principais debates inerentes ao desenvolvimento nacional, já que combatem políticas de Estado afins com o aumento da projeção de seus países no sistema internacional.

Como destacado por Costa (2008), toda a história do século XX - seja da Alemanha, dos Estados Unidos, do Japão ou da URSS - foi marcada pelo sucesso das teses do intervencionismo estatal e do planejamento governamental como motores do desenvolvimento, que pressupõe a instrumentalização das forças econômicas pelas forças políticas. Ao proporem um quadro conceitual sistêmico que condiciona o desenvolvimento econômico e social à inevitabilidade de uma revolução

\footnotetext{
12 Refletindo sobre as críticas de setores esquerdistas às alianças policlassistas, o historiador marxista argentino Rodolfo Puiggrós se pronunciou, há décadas, contrário à dinâmica de isolamento político adotada por esses grupos: "Em nossos países, a revolução nacional anti-imperialista faz com que classes sociais com distintos interesses vão à luta, umas que objetivam o capitalismo e outra que buscam o socialismo, e é dentro desse movimento policlassista que a classe trabalhadora deve conquistar sua hegemonia. Fora do movimento policlassista (e ainda mais contra ele) se condena ao isolamento e à esterilidade. Cientes disso, se fazem de surdas as diversas seitas que instam os trabalhadores a se separarem desse conjunto." (PUIGGRÓS, 1986, p. 131, tradução minha).
} 
socialista, os dependentistas não apenas invertem o sentido do conceito de desenvolvimento desigual, como também atribuem às forças econômicas a determinação das movimentações políticas das nações capitalistas, supostamente incapazes de formular projetos autônomos que fujam à suposta estrutura estática do sistema internacional.

São essas confusões que impedem a instrumentalização dessa teoria para questões afins com a grande disputa travada contemporaneamente num cenário global caracterizado, segundo Visentini (2015), por uma conjuntura na qual as potências norte-atlânticas se articulam para empreender uma retomada de espaços, visando a fragilização da recente ascensão de países até então relativamente periféricos. Em seu lugar, o instrumental teórico dependentista tende a centrar esforços na designação dos novos polos regionais como parte de um mecanismo cíclico de fortalecimento do imperialismo das potências centrais. Assim, pouco se debate no seio dessa vertente político-ideológica acerca de como o Brasil poderia se posicionar, enquanto terceiro interessado, diante da grande disputa sistêmica entre Estados Unidos da América e China, talvez a mais relevante das questões que se colocam para a definição da política externa brasileira. Afinal, evidentemente, a contestação pode até ser necessária, mas não é suficiente para, no panorama mais amplo do sistema internacional, garantir a sustentação dos processos de desenvolvimento das nações:

\begin{abstract}
Verificando o curso da história, constata-se que a não inserção direta na mediação é sempre uma posição vantajosa, uma posição estratégica. Esta posição é a de terceiro interessado. (...) Na dialética que se estabelece entre centro e periferia, e entre cultura e barbárie, para melhor se avançar nesse processo deve-se buscar a posição de terceiro interessado, ou seja, deve-se ter a liberdade de transitar. Não se é centro, mas também não se é periferia. Não se é culto, mas também não se é bárbaro. A pretensa neutralidade não o coloca como periférico, apesar dele o ser, não o coloca como bárbaro, que ele não assume. A neutralidade aparente, a posição de terceiro interessado, evita a mossa decorrente do choque direto. pode vir a posicioná-lo como a alternativa a ser buscada por atores diretos. Em síntese, olhando o processo da civilização, verifica-se que a contestação é necessária, mas não é suficiente. Sempre será melhor ter alguém envolvido, que assuma diretamente a posição de maior contestador (COSTA, 2008, p. 427, grifos meus).
\end{abstract}

Ao invés de elucidar possíveis variantes de ascensão civilizacional, a TMD reafirma, portanto, uma perspectiva de emancipação dos povos resultante daquilo que 
Roberto Campos (1990) designava, ironicamente, como de obtenção do desenvolvimento por decreto - nesse caso específico, a ser decretado pela tomada do poder por grupos políticos alinhados com determinada visão de mundo. Certa vez, José Guilherme Merquior apontou a teoria da dependência como um fruto do subdesenvolvimento cultural latino-americano (HAGE, 2013), uma colocação um tanto excessiva. No entanto, não restam dúvidas: almejando construir um arcabouço conceitual de subversão à ordem global, as formulações dependentistas mais forneceram elementos para a própria reafirmação de seu status quo hierárquico do que o contrário, enfatizando a inevitabilidade de mecanismos de entrave ao desenvolvimento periférico e desdenhando de consistentes projetos alternativos às estruturas de poder do sistema internacional.

\section{Conclusão}

O artigo visou analisar o conceito de subimperialismo, verificando sua formulação originária, sua aplicação para caracterizar a dimensão sul-americana da política externa dos governos Lula e sua validade para esse fim. Corroborando a hipótese, o trabalho apresentou as limitações do conceito nas tentativas de definição da atuação brasileira no período, e também contradições de alguns de seus principais sustentáculos frente às teorias às quais visa dar continuidade. Curiosamente, a estrutura analítica e as movimentações políticas derivadas do dependentismo terminam por reafirmar certos paradigmas que, discursivamente, reivindicam antagonizar.

Longe de constituírem sentenças definitivas, as análises aqui expostas fomentam um debate importante para os rumos da política externa brasileira, da integração regional e das relações entre países sul-americanos. Para além dessas dimensões, as polêmicas acerca do conceito de subimperialismo e dos principais vetores da Teoria Marxista da Dependência também fazem parte do contexto mais amplo das temáticas vinculadas às teorias das relações internacional e do desenvolvimento, e, especialmente, ao conjunto dos segmentos derivados do marxismo e das teorias do imperialismo. Assim, espera-se que, da interlocução desses escritos com as demais pesquisas correntes, se possam estabelecer diálogos 
resultantes no aprofundamento da compreensão acerca dos complexos fenômenos internacionais contemporâneos.

\section{Referências}

BANDEIRA, Luiz Alberto Moniz. Fórmula para o caos: a derrubada de Salvador Allende (1970-1973). Rio de Janeiro: Civilização Brasileira, 2008.

BERRINGER, Tatiana. A burguesia interna brasileira e a integração regional da América do Sul (1991-2016). Oikos 16 (1): 15-29, 2017.

$115-127,2013$. A tese do subimperialismo em questão. Crítica Marxista 36:

BORÓN, Atílio. América Latina en la geopolítica del imperialismo. Buenos Aires: Ediciones Luxemburg, 2013.

BRESSER-PEREIRA, Luiz Carlos. As três interpretações da dependência. Perspectivas 38: 17-48, 2010.

CAMPOS, Roberto. O século esquisito. Rio de Janeiro: Topbooks, 1990.

CARCANHOLO, Marcelo Dias. O atual resgate crítico da teoria marxista da dependência. Trabalho, Educação e Saúde 11 (1): 191-205, 2013.

CARCANHOLO, Marcelo Dias; SALUDJIAN, Alexis. Integración latinoamericana, dependencia de China y sub-imperialismo brasileño en América Latina. Mundo Siglo XXI 29 (8): 43-62, 2013.

COSTA, Darc. Fundamentos para o estudo da estratégia nacional. Rio de Janeiro: Paz e Terra, 2008.

COUTO, Leandro. Relações Brasil-América do Sul: a construção inacabada de parceria com o entorno estratégico. Em: LESSA, Antônio Carlos; ALTEMANI, Henrique (Org.). Parcerias estratégicas do Brasil: os significados e as experiências tradicionais. Belo Horizonte: Fino Traço, 2013.

DOS SANTOS, Theotônio. A teoria da dependência: um balanço histórico e teórico. Rio de Janeiro: Civilização Brasileira, 2000.

Subdesarrollo y dependencia. Em: Lowy, Michael. El marxismo en América Latina. Santiago: LOM Ediciones, 2007.

FERNANDES, Luís. A revolução bipolar: a gênese e derrocada do socialismo soviético. São Paulo: Anita Garibaldi, 2017.

O enigma do socialismo real: um balanço crítico das principais teorias marxistas e ocidentais. Rio de Janeiro: Mauad, 2000. 
FONSECA, Pedro Cezar Dutra. Desenvolvimentismo: a construção do conceito. IPEA - Texto para discussão 2103: 1-67, 2015.

FONTES, Virgínia. A incorporação subalterna brasileira ao capital-imperialismo. Crítica Marxista 36: 103-113, 2013.

GUDYNAS, Eduardo. O novo extrativismo progressista na América do Sul: teses sobre um velho problema sob novas expressões. Em: LÉNA, Philippe; DO NASCIMENTO, Elimar Pinheiro (orgs.). Enfrentando os limites do crescimento: sustentabilidade, decrescimento e prosperidade. Rio de Janeiro: Garamond, 2012.

HAGE, José Alexandre Altahyde. A teoria da dependência: uma contribuição aos estudos de relações internacionais. Revista Política Hoje 22 (1): 106-136, 2013.

HALLIDAY, Fred. Revolution and world politics: the rise and fall of the sixth great power. Londres: MacMillan Press, 1999.

LENIN, Vladimir llitch. O imperialismo: etapa superior do capitalismo. Campinas: Navegando, 2011.

LÓPEZ, Fernando Carnebia; LIMA, Rafael Teixeira de. Ruy Mauro Marini y el subimperialismo brasileño en Bolivia y Paraguay en el siglo XXI. Cadernos Cemarx 9: 69-88, 2016.

LOSURDO, Domenico. Fuga da história? A revolução russa e a revolução chinesa vistas de hoje. Rio de Janeiro: Revan, 2009.

LUCE, Mathias Seibel. A teoria do subimperialismo em Ruy Mauro Marini: contradições do capitalismo dependente e a questão do padrão de reprodução do capital. Tese de doutorado, Universidade Federal do Rio Grande do Sul, 2011.

$\overline{\text { Tensões Mundiais } 10}$ (18): 46-65, 2014.

O subimperialismo, etapa superior do capitalismo dependente.

MARINI, Ruy Mauro. A dialética da dependência. Germinal: marxismo e educação em debate 9 (3): 325-356, 2017.

El subimperialismo brasileño. Centro de Estudios SocioEconómicos (CESO): 1-11, 1971.

Eje militar Brasil-Argentina y subimperialismo. Arauco 71: 19-25,

1965

1974

Subdesarrollo y revolución. Buenos Aires: Siglo XXI Editores,

NOGARA, Tiago Soares. Domenico Losurdo e as revoluções marxistas. Revista de Ciências Sociais Unisinos 55 (1): p. 124-125, 2019. 
Teoria da Dependência: leninismo às avessas e perpetuação do subdesenvolvimento. 2019. Disponível em: $<$ https://portaldisparada.com.br/economia-e-subdesenvolvimento/teoria-dadependencia/amp/> Acessado em 11 de maio de 2020.

OLIVEIRA, Henrique Altemani de. Brasil e China: cooperação sul-sul e parceria estratégica. Belo Horizonte: Fino Traço, 2012.

PAUTASSO, Diego. China e Brasil na África Subsaariana e a retomada da questão nacional. Tensões Mundiais 9 (17): 61-82, 2013.

Desenvolvimento e poder global da China: a política Made in China 2025. Austral: Revista Brasileira de Estratégia e Relações Internacionais 8 (16): 183-198, 2019.

PAUTASSO, Diego; NOGARA, Tiago Soares; COLÓRIO, Augusto Gabriel; WOBETO, Victor Leão. $O$ cerco multidimensional à Teerã e a aproximação sino-iraniana. Tensões Mundiais, 15 (29): 165-182, 2019.

PUIGGRÓS, Rodolfo. Historia crítica de los partidos políticos argentinos II: las izquierdas y el problema nacional. Buenos Aires: Hyspamérica Ediciones Argentinas, 1986.

RICUPERO, Rubens. A diplomacia na construção do Brasil, 1750-2016. Rio de Janeiro: Versal Editores, 2017.

SANTOS, Leandro. BNDES: internacionalização de empresas e o subimperialismo brasileiro. Geousp - Espaço e Tempo (Online) 22 (1): 115-137, 2018.

VISENTINI, Paulo Fagundes. As relações diplomáticas da Ásia: articulações regionais e afirmação mundial (uma perspectiva brasileira). Belo Horizonte: Fino Traço, 2012. O caótico século XXI. Rio de Janeiro: Alta Books, 2015.

ZIBECHI, Raúl. Brasil potencia: entre la integración regional y un nuevo imperialismo. Lima: Programa Democracia y Transformación Global, 2013.

Recebido em: 14/08/2019

Aprovado em: 14/05/2020 